\title{
Utilizing Knowledge Management in Education: The Case of "The University of Jordan"
}

\author{
http://dx.doi.org/10.3991/ijet.v8i1.2463 \\ Dr. Osama. Rababah ${ }^{1}$, Dr. Muhannad Al-Shboul ${ }^{1}$, Dr. Fawaz A. AL Zaghoul ${ }^{2}$ \\ ${ }^{1}$ The University of Jordan, Amman, Jordan \\ ${ }^{2}$ The Computer Center Director the University of Jordan, Amman, Jordan
}

\begin{abstract}
Knowledge as a result of processing the relevant information which is collection of raw data, facts, measurements, and statistics, requires sensitive management that leads educators and learners to increase concern for knowledge management, especially in the educational field.
\end{abstract}

This paper intends to present this proposed approach directly to the one of its main sources of creation; Education. After the introductory part, the paper presents the Knowledge Management in the context of "The University of Jordan” emphasizing every components of knowledge management: people, process, and technology.

Then, the researchers will show the result of the survey which had been carried out on 140 students at The University of Jordan, the survey was about their perceptions regarding the utility and quality of knowledge they gained through their studying at The University of Jordan.

Index Terms-E-learning, higher education, knowledgebased systems, technology and information systems.

\section{INTRODUCTION}

Knowledge Management (KM) is one of the hottest topics nowadays in industry world and to many of information research; as we need it in our daily life, we deal with huge amount of data and information, these data and information have no value until we add value to be "knowledge [1].

Knowledge management is the process to help organization, identify, select, organize, disseminate, and transfer information. It enables problem-solving, dynamic learning, strategic planning, and decision making [2]. KM brings together three core organizational resources: people, process, and technologies to enable the organization to use and share information more effectively. It is much useful to consider the educational institute as adaptive and social system where people cooperate to achieve common purposes. The educational institutes grow and revitalize themselves, through: the knowledge they create plus process for passing that knowledge to their staff, and through the exchanges and relationships that they foster among students, faculty members, and administrative staff in their campuses. The educational institutes face challenges that many non-profit and forprofit institutes seek to share information and knowledge among students and teachers, students and books, or even students themselves; they responsible for passing along knowledge through technical systems to generate data and information and facilitate sharing them [3].
Still there is no single definition for knowledge management [4]. However, Human-centered approach for knowledge management view the organization as complex systems that springs from the unique organizational context they are developed.

As mentioned above, KM has three key cores or realms: people, process, and technologies and information systems.

- People: promote policies and practices them which are developed by the organization, KM are built upon collegial, professional teamwork by active engaged people at many organizational levels. People or staffs in one educational institute are at the center of innovation.

- Process: formal and informal procedure, development process, information sharing patterns, salary incentives, and other many work practice affect information flow, process executes whether or not people choose to participate. Processing tool; audits, maps, knowledge assessment, and improvement plan help in establishing process enable people to get information they need, and when they need it, and to share it, or benefit from it.

KM processes are: Knowledge creation: knowledge is created explicit (on paper or electronic format) or tacit (on the mind of people) knowledge, Generating new ideas, routines, and insights modes.

Knowledge sharing: Willing explanation to another directly or through an intermediary. Knowledge seeking: Knowledge sourcing and utilization [5].

Knowledge acquisition research supports the generation of knowledge-based systems through the development of principles, techniques, methodologies and tools. What differentiates knowledge-based system development from conventional system development is the emphasis on in-depth understanding and formalization of the relations between the conceptual structures underlying expert performance and the computational structures capable of emulating that performance [6].

- Technology and information systems: technology must be recast as vital contributor to the health and effectiveness for the educational institute, not as cost puts strain on the limited resources of the institute, or drivers for KM. However, the best way to apply the technology to $\mathrm{KM}$ is to combine between understanding the fact said that there were limits on infor- 
mation technology which requires global tends toward the value of technology, and the availability of information technology have been expressly designed knowledge management in view [7]. ${ }^{7}$

\section{LITERATURE REVIEW}

In recent years there have been technological changes and great strides in the discoveries, in the presence of innovations and the need for innovative ideas, it became necessary to have a educational professionals qualified to keep up with these changes. Higher education is one of the most important sources of knowledge, the level of professionalism has become required strongly in universities, and educational professionals as key agent have to participate in developing research, bridging the gap between technology and pedagogy [8].

Knowledge is essential to the growth and progress; the researchers mentioned in another on going research about knowledge-based society and the importance of information and communication technology and the education sector in the construction of knowledge.

Many of the ingredients and intellectual qualities become required to the graduates with technological skills, flexibility and adoption, critical and creative thinking, ability to deal with well-defined problem, long-life learning, all these through the effective use of knowledge [9]. While few have disagreed that these attributes are important, there have been questions whether university graduates have sufficiently develop these capabilities. There have been many claims from employers, government, even academics that graduates are ill-prepared for employment which not demanding the requirement of knowledge way [9].

Higher education institutes have "significant opportunities to apply knowledge management practices to support every part of their mission. Knowledge management should not strike higher education institutes as a radically new idea; rather it is a new spin on their raison. The problem is that it is such a wide open area of study that it is difficult to understand the implications of knowledge management for an educational setting. This digest offers a basic introduction to the potential of KM for higher education [10].

\section{KNOWLEDGE MANAGEMENT IN "THE UNIVERSITY OF JORDAN"}

The University of Jordan (UJ) is a public university located in Amman, Jordan. Founded in 1962, it is the largest and oldest institute of higher education in the Hashemite Kingdom of Jordan. The University of Jordan has the highest admission averages in the country with rank 1 and 21among Arab states and 601 among all world according to QS scale (2012), and is considered the premier university in Jordan and one of the most prestigious in the Arab World.

The University of Jordan offers undergraduate and graduate degrees in 24 colleges (faculties) (19 colleges in Amman and 5 in Aqaba, with 201 different specializations [11].

\section{- People:}

The University of Jordan includes more than 5500 employees eligible to be selected based on tests in their fields and vocational academy, including 1628 Profes- sors and teaching staff from recognized universities, 35 of them are researchers, the university has an increase in the number of faculty members of the newly established technological colleges and departments with some stable periods without hiring teaching staff [11] as shown in Figure 1.

\section{- Process:}

knowledge creation, sharing, and utilizing are promoting via research culture. The University of Jordan, since its establishment, has realized the importance of research and its role in knowledge management. As part of the philosophy and mission of pursuing distinction amongst its activities in establishing a cultural passion for research and discovery and in supporting, promoting its tools. For this reason, The University of Jordan has entrusted special diligence to scientific research and founded in the year 1973, the Deanship of Academic

Research (DAR). The deanship is responsible for organizing, supervising, promoting, and supporting academic research as the means for vast development and technological advancement. The role that DAR is playing in augmenting and expanding human knowledge is recognized through persistently seeking ways and new endeavors to encourage, develop, promote and support scientific activities both locally and internationally. The deanship has largely concentrated and carefully considered modernizing and developing its tools to include interdisciplinary research with emphasis on integrated and comprehensive tracks in all disciplines. The deanship aims at achieving the university's objective of helping faculty members at the university to push their research to internationally recognized levels and to promote scientific knowledge. The deanship provides researchers with whatever support they need, from the latest equipment, to programs that help them accomplish their research proposals in the best possible manner.

The Deanship of Academic Research takes at its own the following responsibilities: funding research projects conducted by faculty members and other university personnel. DAR ensures that most of applied research proposals are funded locally or from agencies within Jordan and international institutions. Publishing original research proposals, studies, books, translations and manuscripts. Issuing studies, a refereed set of journals published in seven different fields (Deanship of Research Department, 2012) [12].

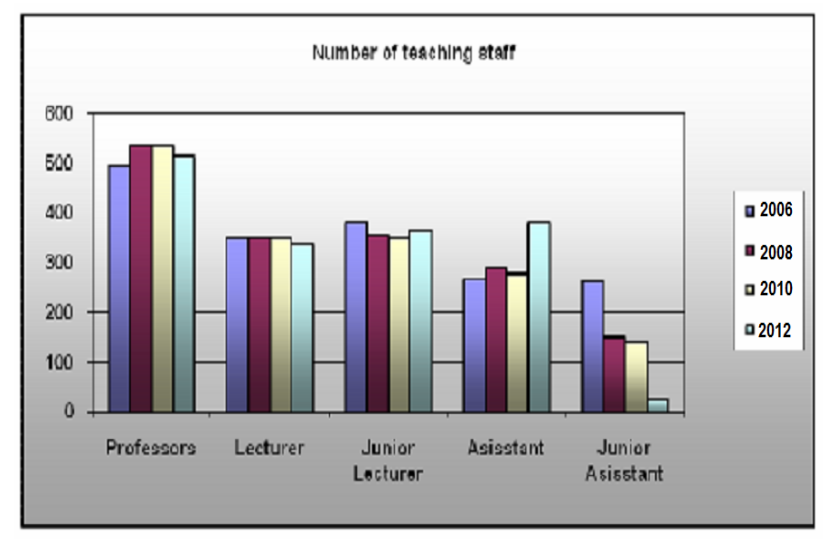

Figure 1. Number of teaching staff. 
- Technology and Information Systems: The University of Jordan has integrated system in information technology, and Website regard to providing educational resources and student services starting the online registration, and through all activities of electronic communication between students and teaching staff and employees, and it in the process E-learning, online admission.

\section{THE PERCEPTIONS OF THE STUDENTS REGARDING THE QUALITY OF KNOWLEDGE PROVIDED.}

The perceptions of the students about the quality of knowledge provided by The University of Jordan were emphasized through a static survey distributed in September 2012 using random sample. It included 142 students from 22 specializations, 10 faculties ranging from second year to final year graduates with percentages as shown in the Table I.

TABLE I.

JU GRADUATES PERCENTAGES

\begin{tabular}{|l|l|l|l|l|}
\hline Second & Third & Fourth & Fifth & Sixth \\
year & year & year & year & year \\
$32 \%$ & $44 \%$ & $14 \%$ & $8 \%$ & $2 \%$ \\
\hline
\end{tabular}

First, the researcher asked them whether they had chosen their specialization according to prior plan or not, surprisingly, 50\% of answers were "YES", and 50\% were "NO".

secondly, the graduates were asked about their ideas and thoughts about their specializations as joining (that was for both YES-NO answers) or when choosing their specializations (that was for YES-answers), the most common responses were concern about getting job, higher wages, or desire in a specialty, some of them want to try it after being failed in another one, and some people advice them to choose specific specialization; the results are shown below in Figure 2.

Figure 2 show that most students had chosen their specializations because they think they could have jobs with whereas less than half of students had chosen specialization based on desiring. This study reveals that few students may have lake for recognition for the nature of their professions in the future, or tend to be innovative and have knowledge. However, some researchers argue that it is not necessarily to be a relationship between desiring something and having knowledge.

Because few students have information about their future career, the researchers asked them about the chances they will have to be employed after graduation in the same specialization. The optimists who answered "high" were $47 \%$; unfortunately $37 \%$ of students were having no idea about future career (see Figure 3). This means that their information stills raw. In this occasion, the next question was "How much knowledge do you think you had during studying and you will apply (or applying in the practice (for worker students))?"; most of them think they reached $25-50 \%$ of knowledge in their specializations as shown in Figure 4.

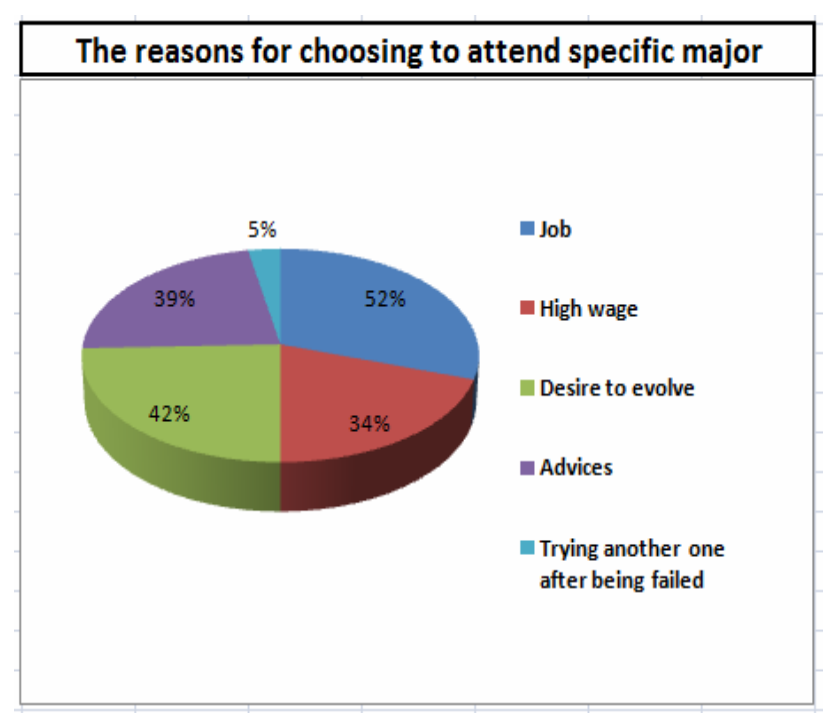

Figure 2. The Reasons for choosing to attend Specific Major.

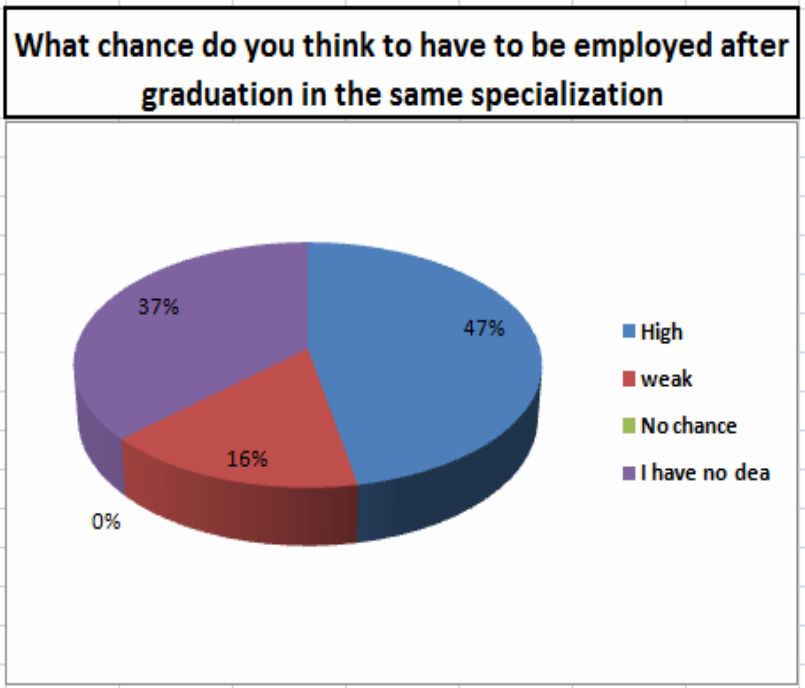

Figure 3. What Chances the students to be employed after Graduation in the same Specialization.

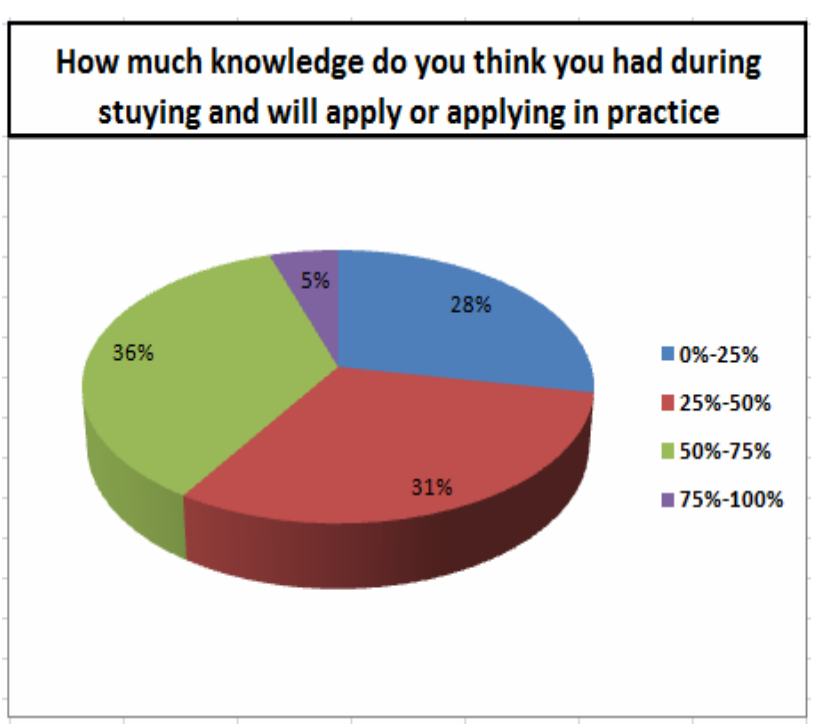

Figure 4. How much Knowledge the student had during his/her studying. 
Although most of students were complaining from less connection between training they received in their colleges and the reality in the labor market, their responses for the inquiry whether they want to work in the same field of specialization after graduation were $85 \%$ of students prefer to work with their certification, this reflects the willingness to arrange their raw knowledge to be real knowledge in the labor market, only 5\% are careless to work in the same field of their specialization (see Figure 5).

Only 3\% are worker students, their imagination about creation their own and creative business still varying, as they were asked "do you think to start own business after graduation”. $64 \%$ are prefer to create their own business in the same field of specialization, 7\% don't care about the type of business, and $29 \%$ have no willingness to create such businesses, this variation as a result that some students feel that their specialties is required by the labor market and they we felt in the best position. Some felt ambitious to develop their knowledge and direct it to become innovative in the labor market, and some of them feel that specialization is not required and think seriously deviating from his knowledge.

\section{CONCLUSION.}

The researchers can say that The University of Jordan is in continuous progress in the process of knowledge management. The university faculty members and researchers are able to direct data to education to become knowledge and this in itself depends on the students. Students have to have a good idea somewhat about their specialization courses and a clear vision for their future careers, but they may lack of the realism in the perceptions of building private business and labor market situation. Therefore the economic factor remains of the most important factors that play a role in directing knowledge management. In general, the situation of information technology and computerized systems at the public universities in Jordan remains in a good level, which in turn plays a key role in knowledge creation and utilization, providing the student and the process, and the entire staff opportunities to locate and make a good use of knowledge.

\section{REFERENCES}

[1] Chan, J.O. (2009), Integrating knowledge management and relationship management in an enterprise environment, Communications of the IIMA.

[2] Urban, Aronson, and Liang. (2005). knowledge management. In: Turban, Aronson, and Liang decision support systems and intelligent systems. USA: Prentice hall.

[3] Rezende, R., and Souza, J. "Using knowledge Management Techniques to Improve the Learning Process through the Exchange of Knowledge Chains," 11th International Conference on Computer Supported Cooperative Work in design, 2007, pp. 681 686.

[4] Filemon A. Uariarte, Jr. (2008) "Introduction to Knowledge Management”, ASEAN Foundation, Jakarta, Indonesia.

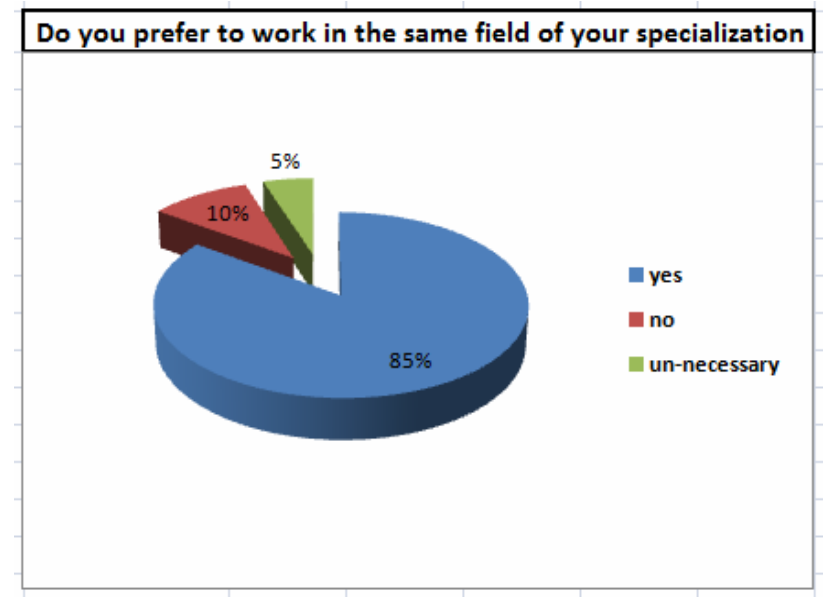

Figure 5. Work Preference

[5] Rao R. Nemani, (2010) "The Role of Computer technologies in knowledge acquisition”. Journal of Knowledge Management Practice. Vol. 11, No. 3, September 2010.

[6] David Corsar (2009), Developing Knowledge-Based Systems through Ontology Mapping and Ontology Guided Knowledge Acquisition, PhD thesis, Department of Computing Science, University of Aberdeen, 2009.

[7] Farmer, Johannes; Lindstaedt, Stefanie N.: AD HOC: Workintegrated Technology Supported Teaching and Learning, Proceedings of Organizational Knowledge, Learning and capabilities, Innsbruck, Austria (2004)

[8] Lisa A. Peterides, Thad R. Nodine (2003). Knowledge management in education - defining the landscape. USA: the institute of knowledge management. P10-p17M. Young, The Technical Writer's Handbook. Mill Valley, CA: University Science, 1989.

[9] Hansen, Randall, and Hansen Katharine. 2010. What do Employers Really Want? Top Skills and Values Employers Seek from Job-Seekers. Quintessential Careers. http://www.quintcareers.com/job_skills_values.html

[10] Malcolm Tight, (2012). Researching higher education, 2nd Ed, Open university press, Berkshire England 2012.

[11] University of Jordan, Unit of media and public relations and cultural. (2012). facts and Statistics 2011-212. Facts and Statistics 2011-212. 36 (1), p5-p9.

[12] Deanship of Research Department. (2012). Deanship of Research Department. Available: http://www.ju.edu.jo. Last accessed 15th Aug 2012

\section{AUTHORS}

Dr. Osama Rababah is with the Department of Business Information Technology, The University of Jordan, Amman, CO 11942 Jordan (o.rababah@ ju.edu.jo).

Dr. Muhannad Al-Shboul, is with the Department of Curriculum and Instruction, The University of Jordan, Amman, CO 11942 Jordan (malshboul@ju.edu.jo).

Dr. Fawaz A. AL Zaghoul is with the Department of Computer Information Systems, The University of Jordan, Amman, CO 11942 Jordan (fawaz@ ju.edu.jo).

Received 24 December 2012. Published as resubmitted by the authors 27 February 2013. 